\title{
Mobilization of Calcium from Intracellular Stores, Potentiation of Neurotransmitter-Induced Calcium Transients, and Capacitative Calcium Entry by 4-Aminopyridine
}

\author{
Maurizio Grimaldi, ${ }^{1}$ Marco Atzori, ${ }^{2}$ Pulak Ray, ${ }^{1}$ and Daniel L. Alkon ${ }^{3}$ \\ ${ }^{1}$ Laboratory of Adaptive Systems, National Institute for Neurological Disorders and Stroke and ${ }^{2}$ National Institute of \\ Deafness and other Communicative Disorders, National Institutes of Health, Bethesda, Maryland 20892, and ${ }^{3}$ Blanchette \\ Rockefeller Neurosciences Institute, Rockville, Maryland 20850
}

In this study we analyzed the effect of 4-aminopyridine (4-AP) on free cytosolic calcium concentration $\left(\left[\mathrm{Ca}^{2+}\right]_{i}\right)$ in basal conditions, after stimulation with neurotransmitters, and during capacitative calcium entry.

Using fura-2 ratiometric calcium imaging, we found that 4-AP increased $\left[\mathrm{Ca}^{2+}\right]_{\mathrm{i}}$ in type I astrocytes, neurons, and in skeletal muscle cells. The $\left[\mathrm{Ca}^{2+}\right]_{i}$ elevation induced by 4-AP was concentration-dependent and consisted of two phases: the first was dependent on intracellular calcium mobilization, and the second was dependent on extracellular calcium influx. 4-AP also increased the second messenger inositol trisphosphate in both neurons and astrocytes.

In astrocytes, 4-AP treatment potentiated the sustained phase of the $\left[\mathrm{Ca}^{2+}\right]_{i}$ elevation induced by ATP and bradykinin. In addition, capacitative calcium entry was potentiated severalfold by 4-AP, in astrocytes and muscle cells but not in neu- rons. These effects of 4-AP were completely and promptly reversible. 4-AP blocked voltage-sensitive $\mathrm{K}^{+}$currents in astrocytes. However, voltage-sensitive $\mathrm{K}^{+}$channel blockers inhibiting these currents did not affect agonist-induced calcium transients or capacitative calcium entry, indicating that 4-AP effects on $\left[\mathrm{Ca}^{2+}\right]_{i}$ were not caused by the blockade of voltagegated $\mathrm{K}^{+}$channels.

We conclude that 4-AP is able to affect calcium homeostasis at multiple levels, from increasing basal $\left[\mathrm{Ca}^{2+}\right]_{\mathrm{i}}$ to potentiating capacitative calcium entry. The potentiation of capacitative calcium entry in astrocytes or muscle cells may explain some of the therapeutic activities of 4-AP as a neurotransmission enhancer.

Key words: neuron; astrocytes; muscle cell; capacitative calcium entry; intracellular calcium stores; voltage-sensitive $\mathrm{K}^{+}$ potassium channels 4-aminopyridine (4-AP) and related molecules have been widely recognized for their ability to block voltage-sensitive $\mathrm{K}^{+}$channels (Aronson, 1992). 4-AP has also been used as a therapeutic agent in many neurological and neuromuscular junction disorders. A number of reports address the beneficial role of 4-AP and related compounds in multiple sclerosis (Schwid et al., 1997; Fujihara and Miyoshi, 1998), myasthenia gravis (Li and Zhang, 1994), and in the canine model of motoneuron disease (Pinter et al., 1997). Clinical applications of 4-AP have been extended to traumatic spinal cord injury (Segal et al., 1999) and to neurodegenerative disorders such as Alzheimer's disease (Andreani et al., 2000). In all these instances, 4-AP has been thought to improve symptomatology through the blockade of voltage-activated $\mathrm{K}^{+}$channels, in turn, causing neuronal depolarization and potentiation of neurotransmission (Smith et al., 2000).

There are, however, a number of reports addressing a possible direct effect of 4-AP on calcium homeostatic mechanisms (Glover, 1981; Agoston et al., 1983; Furukawa et al., 1985; Fu et al., 1987; Gibson and Manger, 1988; Gobet et al., 1995; Fryer and Glover, 1997). In this study, we analyzed how 4-AP may affect calcium homeostasis. To this end, we analyzed the effect of 4-AP on intracellular calcium homeostasis in cortical type I astrocytes, primary cortical neurons, and skeletal muscle cells using fura-2

Received Nov. 28, 2000; revised Jan. 18, 2001; accepted Jan. 30, 2001.

Correspondence should be addressed to Dr. Maurizio Grimaldi, Department of Neurology, Uniformed Services of the Health Sciences, 4301 Jones Bridge Road, Bethesda, MD 20814-4799. E-mail: mgrimaldi@usuhs.mil.

Copyright (C) 2001 Society for Neuroscience 0270-6474/01/213135-09\$15.00/0 ratiometric calcium imaging. We provide evidence here for three novel actions of 4-AP, unrelated to its ability to block voltagesensitive $\mathrm{K}^{+}$channels. We show that 4-AP regulates calcium homeostasis by elevating inositol trisphosphate levels and therefore causing calcium release from intracellular calcium stores (ICS), by potentiating capacitative calcium entry (CCE) and therefore agonist-evoked calcium transients.

\section{MATERIALS AND METHODS}

Preparation of primary cultures of cortical type I astrocytes. Embryonic type I astrocyte cultures were obtained from embryonic day 17 rat fetuses, according to a published protocol, with slight modifications (Grimaldi et al., 1994). Briefly, fetuses were obtained by means of $\mathrm{C}$-section from a $17 \mathrm{~d}$ pregnant Wistar rat and quickly decapitated. The heads were placed in PBS (Life Technologies, Gaithersburg, MD) containing $4.5 \mathrm{gm} / 1$ of glucose. Cerebral cortices were dissected, minced, and enzymatically digested with papain (Worthington, Freehold, NJ). The tissue fragments were then mechanically dissociated. The cells in suspension were counted and plated in $25 \mathrm{~cm}^{2}$ flasks $\left(10^{6}\right.$ cells per flask). Medium was changed after 6-8 hr, to wash away unattached cells. Subsequently, the medium was changed every $2 \mathrm{~d}$. This yielded cultures consisting of $95 \%$ or more type I astrocytes, as characterized by glial fibrillary acidic protein (GFAP) immunoreactivity (Grimaldi et al., 1999).

Primary cultures of cortical neurons. Neuronal cultures were prepared as described above, with some modifications (Grimaldi and Cavallaro, 1999). Briefly, after obtaining the cell suspension, we counted and tested the cells for viability using the trypan blue exclusion test (viability was $>97 \%$ ). Cells were then plated on poly-L-lysine and collagen-coated glass coverslips in 12 multiwell plates. After $96 \mathrm{hr}, 10 \mu \mathrm{M}$ of fluorodeoxyuridine was added to the medium to inhibit glial cell division, while the medium was supplemented with $10 \mu \mathrm{M}$ uridine to allow mRNA synthesis. 
Figure 1. Effect of 4-AP on $\left[\mathrm{Ca}^{2+}\right]_{\mathrm{i}}$. Near-confluent cultured type I astrocytes were loaded with fura-2. Cells were perfused with increasing 4-AP concentrations applied at the times indicated by the top broken line arrows and washed at the times indicated by the solid line arrows below the trace. Increasing concentrations of 4-AP caused proportional $\left[\mathrm{Ca}^{2+}\right]_{i}$ elevation that reached an apparent plateau at $20 \mathrm{mM}$ 4-AP, as shown in the inset. Removal of 4-AP caused a prompt return to baseline $\left[\mathrm{Ca}^{2+}\right]_{\mathrm{i}}$. The $\mathrm{EC}_{50}$ of 4 -AP was $\sim 10 \mathrm{~mm}$.

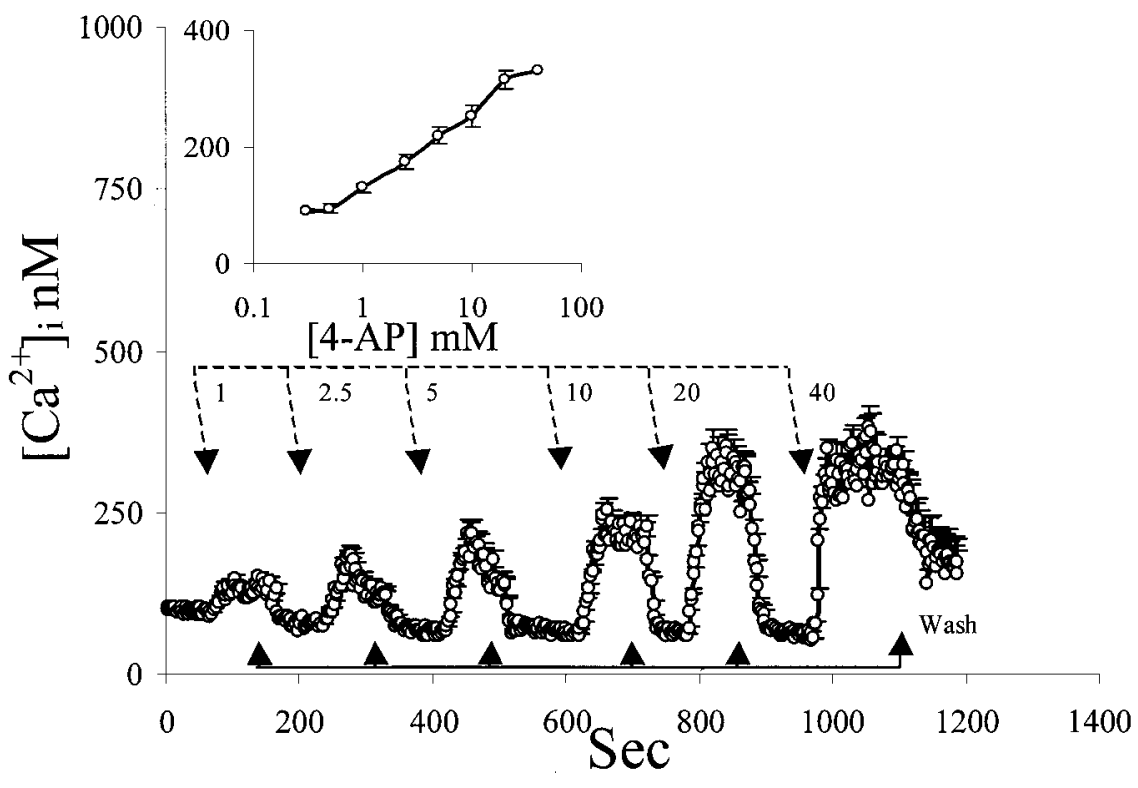

L6 rat skeletal muscle cell line. L6 cells were purchased from the American Tissue Culture Collection (Rockville, MD). On arrival, cells were cultured, expanded, and frozen. Cell aliquots were thawed and used between passage 1 and 5. Cells were maintained in DMEM with 10\% fetal bovine serum (HyClone, Logan, UT) and Pen/Strep (Life Technologies).

Total inositol phosphate accumulation assay. Inositol phosphate ( $\left.\operatorname{InsP}_{\mathrm{t}}\right)$ accumulation was assayed in astrocytes and neurons as previously described (Grimaldi and Cavallaro, 1999; Grimaldi et al., 1999). Briefly, near-confluent astrocyte cultures were switched to serum-free, myoinositol-free DMEM containing $2 \mu \mathrm{Ci} / \mathrm{ml}$ of myo- $\left[2-{ }^{3} \mathrm{H}\right]$-inositol $(30$ $\mathrm{Ci} / \mathrm{mmol}$ ) (American Radiolabeled Chemicals, St. Louis, MO). After 36 $\mathrm{hr}$, cells were rinsed twice in a saline solution (KRB) containing (in $\mathrm{mM}$ ): $\mathrm{NaCl} 125, \mathrm{KCl} 5, \mathrm{Na}_{2} \mathrm{HPO}_{4} 1, \mathrm{MgSO}_{4} 1, \mathrm{CaCl}_{2} 1$, glucose 5.5 , and HEPES 20, pH 7.2. Cells were incubated with KRB containing $20 \mathrm{~mm}$ $\mathrm{LiCl}$ for $20 \mathrm{~min}$ to block $\mathrm{InsP}_{1}$ degradation. Cells were then exposed to testing substances for $90 \mathrm{~min}$, at which time the reaction was stopped with $6 \%$ ice-cold perchloric acid. Supernatants were transferred to test tubes, and acidity was neutralized with a solution containing $9 \mathrm{~mm}$ sodium tetraborate and $0.5 \mathrm{~m}$ potassium hydroxide. Five hundred microliters of the neutralized solution were transferred to a new test tube, to which 750 $\mu \mathrm{l}$ of anionic exchange resin (Dowex AG 1X-8; 100-200 mesh; mixed 1:3 in water) (Bio-Rad, Hercules, CA) was added. The resin was centrifuged and washed with $1 \mathrm{ml}$ of water. InsP $\mathrm{P}_{\mathrm{t}}$ were eluted with $500 \mu \mathrm{l}$ of a solution containing $1.2 \mathrm{M}$ ammonium formate and $0.1 \mathrm{M}$ formic acid solution.
Finally, $200 \mu \mathrm{l}$ of the eluant was transferred to scintillation vials, mixed with $4 \mathrm{ml}$ of scintillation liquid (Biosafe II; RPI, IL) and counted for 4 min. Results were expressed as DPM/well. Each experiment was repeated at least three times, and each data point was run in quadruplicate.

Single cell $\left[\mathrm{Ca}^{2+}\right]_{i}$ measurements. Astrocytes, L6, or neurons were seeded on glass coverslips (Assistent, Germany). Before each experiment, the cells were washed once in KRB and loaded with $2 \mu \mathrm{M}$ fura- 2 AM (Molecular Probes, Eugene, OR) for $22 \mathrm{~min}$ at room temperature, to minimize probe compartimentalization (Roe et al., 1990), under continuous gentle shaking. After loading, the cells were washed once with KRB and then incubated for $22 \mathrm{~min}$ in fura- $2 \mathrm{AM}$-free KRB at room temperature (to minimize the compartmentalization of the probe; Roe et al., 1990), to allow washout of the unesterified probe (Grimaldi et al., 1999). Finally, the coverslips were mounted in a low-volume, self-built $150 \mu \mathrm{l}$ perfusion chamber. Preparations were perf used with calcium or calciumfree KRB saline solution at a speed of $1 \mathrm{ml} / \mathrm{min}$. Experiments were imaged using an inverted microscope equipped with an intensified CCD camera (Videoscope, VA) and a $40 \times$ lens (Zeiss fluar series). Calciumfree KRB contained no added calcium and $100 \mu \mathrm{M}$ EGTA.

Image pairs obtained every $2 \mathrm{sec}$ by exciting the preparations at 340 and $380 \mathrm{~nm}$ were used to obtain ratio images. Excitation wavelengths were changed using a filter wheel (Metaltek), and the emission wavelength was set to $510 \mathrm{~nm}$. Captured images were processed with a Matrox-LC acquisition board and analyzed by using the software MetaFluor (Universal Imaging, West Chester, PA). Regions of interest
500

Figure 2. Characterization of 4-APinduced calcium response in type I astrocytes. $A$, Treatment with $10 \mathrm{~mm}$ 4-AP caused a slow-onset long-lasting $\left[\mathrm{Ca}^{2+}\right]_{i}$ elevation, which was promptly reversed by washout. $B$, When extracellular calcium was removed, 4-AP was still able to increase $\left[\mathrm{Ca}^{2+}\right]_{\mathrm{i}}$. However, the shape of the response was modified to a transient peak with a quick return to baseline. $C$, The effect of 4-AP was tested in the absence of extracellular calcium and after depletion of intracellular calcium stores with thapsigargin (Thap). D, A $10 \mathrm{~mm}$ concentration of 4-AP was applied to astrocytes in calcium-free KRB. Subsequently calcium was reintroduced, and $\left[\mathrm{Ca}^{2+}\right]_{\mathrm{i}}$ was monitored. Perfusion of the testing substances is indicated by the horizontal bars.

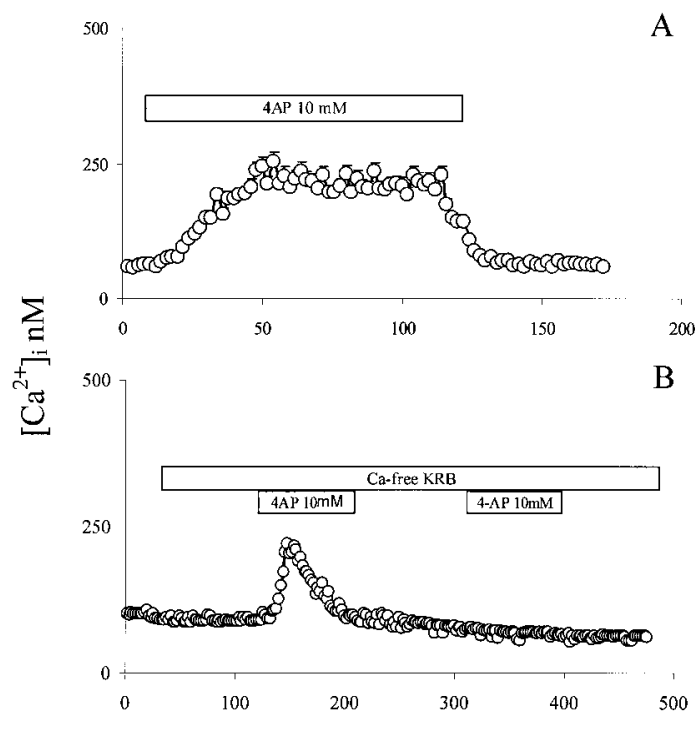

A 500

C
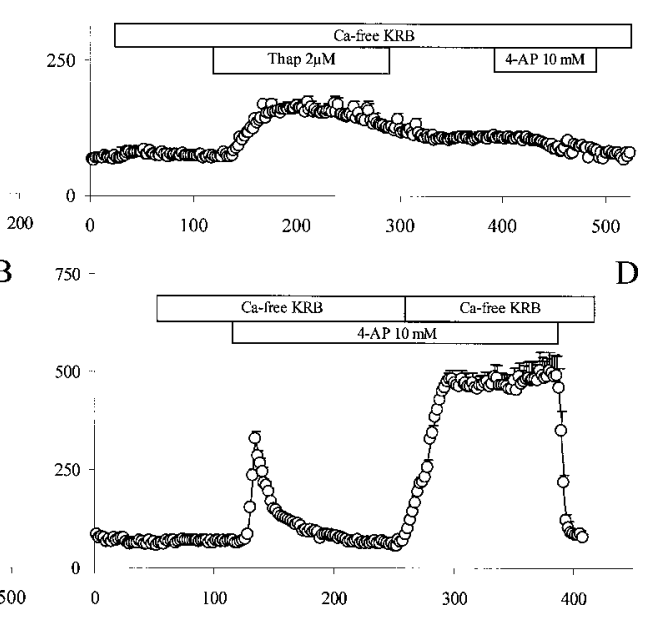


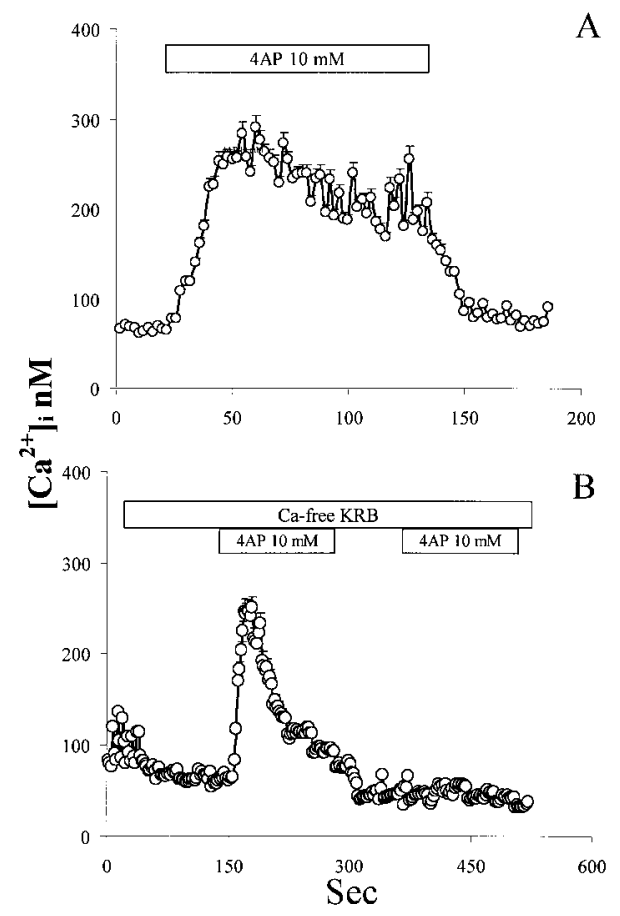

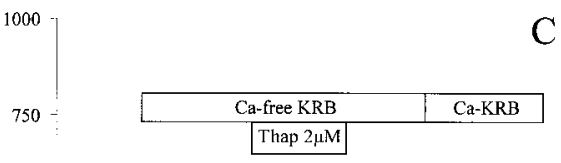
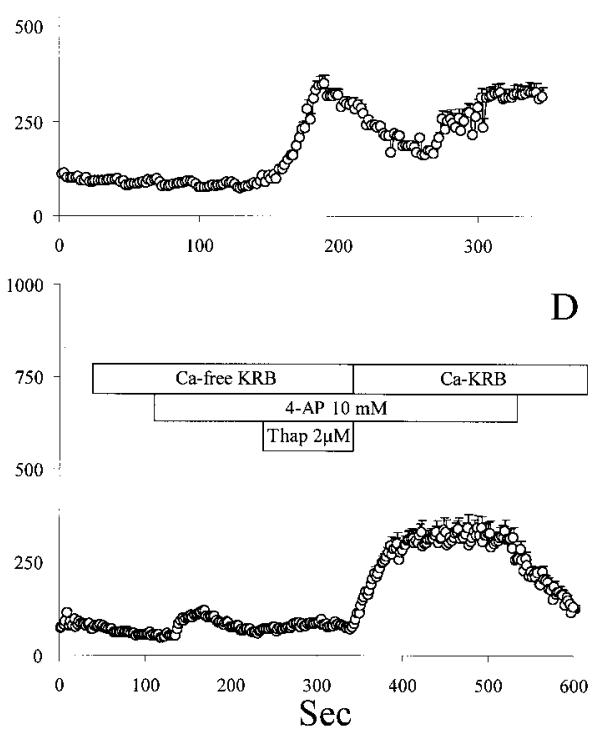

Figure 3. Characterization of 4-AP-induced $\left[\mathrm{Ca}^{2+}\right]_{\mathrm{i}}$ rise in cultured cortical neurons. $A, \mathrm{~A}$ $10 \mathrm{~mm}$ concentration of 4-AP was applied to cortical neurons plated on glass coverslips. The compound caused a slow-onset long-lasting $\left[\mathrm{Ca}^{2+}\right]_{\mathrm{i}}$ elevation. The $\left[\mathrm{Ca}^{2+}\right]_{\mathrm{i}}$ elevation was promptly reversed by washing out the compound. $B$, When extracellular calcium was removed, 4-AP (10 mM) was still able to increase $\left[\mathrm{Ca}^{2+}\right]_{\mathrm{i}}$. However, the response was transient, and $\left[\mathrm{Ca}^{2+}\right]_{\mathrm{i}}$ returned promptly to baseline values. $C$, ICS were depleted in the absence of extracellular calcium with thapsigargin and CCE after reintroduction of calcium was measured. $D$, ICS were depleted with 4-AP in calcium-free medium. The neurons were subsequently exposed to thapsigargin, and $60 \mathrm{sec}$ later calcium was reintroduced in the extracellular solution to elicit CCE. Perfusion of the testing substances is indicated by the horizontal bars. were obtained by delimiting the profile of the cells and averaging the fluorescence intensity within the delimited area. Intensity values were converted to $\left[\mathrm{Ca}^{2+}\right]_{i}$ using different methods for neurons, muscle cells, and astrocytes. Ratio values were calibrated to $\left[\mathrm{Ca}^{2+}\right]_{\mathrm{i}}$ for neurons and muscle cells obtaining $F_{\max }$ and $R_{\max }$ and $F_{\min }$ and $R_{\min }$ by exposing the cells to $10 \mu \mathrm{M}$ ionomycin in presence of $10 \mathrm{~mm}$ calcium. After the maximal signal was obtained, cells were perfused with calcium-free KRB containing 10 mM EGTA. $\left[\mathrm{Ca}^{2+}\right]_{\mathrm{i}}$ in neurons and muscle cells was then calculated using the equation developed by Grynkiewicz et al. (1985). Ratio values were calibrated to $\left[\mathrm{Ca}^{2+}\right]_{i}$ in astrocytes with a titration method. The titration calibration curve was obtained in living cells exposed to known extracellular calcium concentration in the presence of $5 \mu \mathrm{M}$ ionomycin (containing $5.2 \%$ calcium) as previously published (the following are the ratio values measured in astrocytes: $760 \mathrm{~nm} \mathrm{Ca} \mathrm{Caxt}_{\text {t }}$ $\mathrm{R}_{340 / 380}=18 ; 1260 \mu \mathrm{M} \mathrm{Ca}_{\mathrm{ext}} \mathrm{R}_{340 / 380}=32 ; \mathrm{R}_{340 / 380}$ at $0 \mathrm{Ca}_{\mathrm{ext}}=0.29$; $\mathrm{R}_{340 / 380}$ at $10 \mathrm{~mm} \mathrm{Ca} \mathrm{ext}=60$ ) (Grimaldi et al., 1999). Compartmentalization of fura- 2 after loading of the cells in the above specified conditions was assessed to exclude any significant trapping of the probe in organelles. We perfused fura 2-loaded cells with digitonin at $12.5 \mu \mathrm{g} / \mathrm{ml}$ and monitored residual fluorescence in the cells with the excitation set at 360 and emission at $510 \mathrm{~nm}$, the isosbestic point for fura 2. As a result of cell membrane permeabilization, fura- 2 freely diff used from the cytosol to the extracellular space. No significant residual fluorescence was detected inside the cells, indicating negligible probe compartmentalization (data not shown).

Patch-clamp recording. Astrocytes seeded on glass coverslips were washed in KRB, placed in a perfusion chamber, and then perfused continuously. Glass pipettes were pulled (2-3 M 2 ) and filled with a solution containing (in $\mathrm{mM}$ ): $130 \mathrm{~K}^{+}$Gluconate, 10 HEPES, 5 BAPTA, 2 ATP, $0.3 \mathrm{GTP}$, and $1.0 \mathrm{MgCl}_{2}$. Cells were voltage-clamped in the whole-cell configuration using an Axopatch-1D amplifier driven by a personal computer running the pClamp acquisition software (Axon Instruments, Foster City, CA). Data were analyzed off-line using the same software.

Fast and transient currents were measured at the peak, whereas steady-state currents were measured at the end of the voltage pulse, at a delay $\geq 150 \mathrm{msec}$. In a second set of experiments, voltage changes before and after drug application were measured in the current-clamp configuration, after waiting several minutes for membrane voltage stabilization and after adjusting the resting voltage to $-75 \mathrm{mV}$ with a steady current injection. A fixed current pulse inducing a voltage step of $\sim 5 \mathrm{mV}$ was delivered every $8 \mathrm{sec}$ to continuously monitor the cell input resistance. Only cells with stable holding currents before drug application were considered in the analysis.
Materials. All materials were purchased from Sigma (St. Louis, MO), unless otherwise specified in the text.

Use of laboratory animals. Adequate measures were taken to minimize unnecessary pain and discomfort to the animal and to minimize animal use, according to National Institutes of Health regulations on animal handling and care (Guide for the Care and use of Laboratory Animals; National Academy Press, 1996). Pregnant animals were killed by exposure to $\mathrm{CO}_{2}$.

Statistical analyses. Experiments were performed at least three times using different cell preparations. For $\left[\mathrm{Ca}^{2+}\right]_{i}$ measurements, digital images were converted to analog data and imported to a spreadsheet. Numeric values, representing the $\left[\mathrm{Ca}^{2+}\right]_{i}$ determined every $2 \mathrm{sec}$, were averaged, and the SE was calculated. Data are displayed as averages \pm SE. When statistical validation was required, data were analyzed by ANOVA followed by a $t$ test and shown as a bar inset in the corresponding figure. Differences were considered statistically significant when the $p \leq 0.05$.

\section{RESULTS}

\section{Effect of 4-AP on $\left[\mathrm{Ca}^{2+}\right]_{i}$}

4-AP moderately increased $\left[\mathrm{Ca}^{2+}\right]_{\mathrm{i}}$ in cortical type I astrocytes (Figs. 1, 2A), cortical neurons (Fig. 3A), and L6 cells (see Fig. 7B, inset). In astrocytes, increasing concentrations of 4-AP between 1 and $20 \mathrm{~mm}$ caused a linear elevation of $\left[\mathrm{Ca}^{2+}\right]_{\mathrm{i}}$, with an apparent plateau at $20 \mathrm{~mm}$ (Fig. 1, inset). The calculated $\mathrm{EC}_{50}$ was between 5 and $10 \mathrm{~mm}$ of the drug (Fig. 1, inset). The elevation of $\left[\mathrm{Ca}^{2+}\right]_{\mathrm{i}}$ induced by 4-AP had a slow onset and reached a steady-state level that was maintained as long as the drug was applied (Figs. 1, 2A). After washing, calcium concentration returned promptly to baseline values (Figs. 1, 2A). The 4-AP-induced $\left[\mathrm{Ca}^{2+}\right]_{\mathrm{i}}$ elevation did not show desensitization (Fig. 1). Similar results were found in neurons (Fig. $3 A$ ) and in muscle cells (see Fig. 8B, inset).

We analyzed the role of ICS and extracellular calcium in 4-AP-induced $\left[\mathrm{Ca}^{2+}\right]_{\mathrm{i}}$ elevation in astrocytes and in neurons. In the absence of extracellular calcium, 4-AP was still able to elevate $\left[\mathrm{Ca}^{2+}\right]_{\mathrm{i}}$ in both astrocytes and neurons (Figs. $2 \mathrm{~B}, 3 \mathrm{~B}$ ). However, the prolonged sustained phase of $\left[\mathrm{Ca}^{2+}\right]_{\mathrm{i}}$ elevation was absent (Figs. 2B, 3B). Muscle cells displayed a similar behavior (see Fig. $8 B$, inset). These data suggest that this property of 4 -AP is 


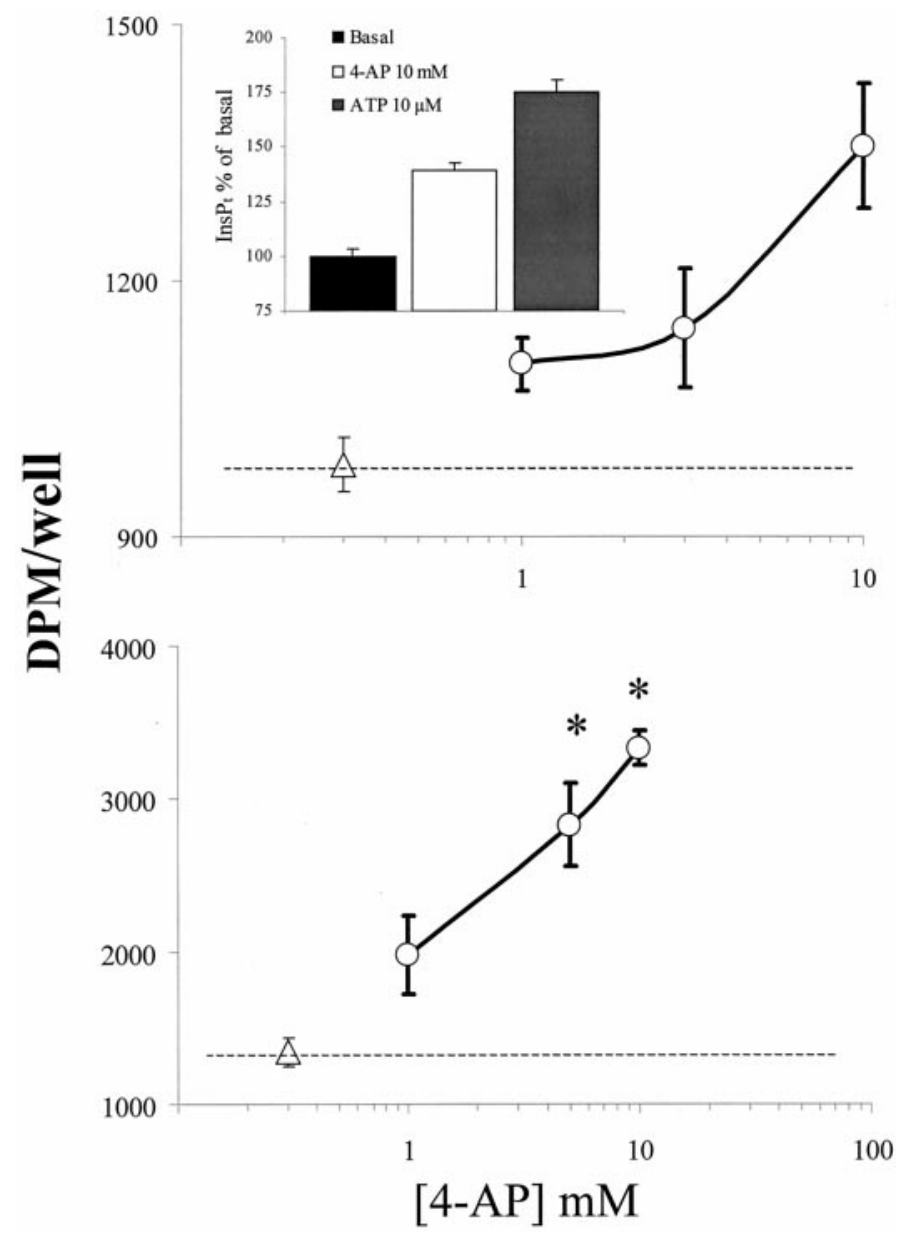

Figure 4. Effect of 4-AP on $\mathrm{InsP}_{\mathrm{t}}$ accumulation in astrocytes and neurons. $A$, 4-AP causes a concentration-dependent elevation of $\operatorname{InsP}_{\mathrm{t}}$ accumulation in type I astrocytes. Compared with the stimulation obtained with a $10 \mu \mathrm{M}$ ATP $\left(\mathrm{EC}_{50}, 30 \mu \mathrm{M}\right), 10 \mathrm{~mm} 4$-AP $\left(\mathrm{EC}_{50}\right)$ was $50 \%$ less powerful (inset). $B$, 4-AP increased $\mathrm{InsP}_{\mathrm{t}}$ production in cortical neurons. Basal values are indicated by the open triangle and the dashed line. ${ }^{*} p \leq$ 0.05 versus basal value.

general rather than cell type-specific. In the absence of extracellular calcium, treatment with thapsigargin prevented 4-APinduced calcium mobilization in astrocytes and neurons (Fig. $2 C$ ). The latter evidence suggests that 4-AP-induced calcium elevation is caused by release of calcium from thapsigargin-sensitive ICS.

\section{4-AP increases Ins $P_{t}$ production}

To test whether the effect of $4-\mathrm{AP}$ on $\left[\mathrm{Ca}^{2+}\right]_{\mathrm{i}}$ was caused by the activation of the phospholipase $\mathrm{C}$ (PLC)/ $\mathrm{InsP}_{3}$ pathway, we measured $\mathrm{InsP}_{\mathrm{t}}$ production, an index of PLC activation, in astrocytes (Fig. 4A) and neurons (Fig. 4B) after exposure to 4-AP. In both cell types, after 4-AP treatment a concentration-dependent increase of InsP production was detected (Fig. 4). Sensitivity of neurons and astrocytes to 4-AP was almost identical. Stimulation of the $\mathrm{InsP}_{\mathrm{t}}$ production caused by 4 -AP $\left(10 \mathrm{mM}\right.$, the $\mathrm{EC}_{50}$ for 4-AP) was not very large, compared with the effectiveness of a less than half-maximal concentration of ATP (Grimaldi et al., 1999) (Fig. 4A, inset).

\section{4-AP potentiates CCE in astrocytes and muscle cells}

Astrocytes exposed to $10 \mathrm{~mm}$ 4-AP in calcium-free buffer released calcium from ICS. The subsequent reintroduction of calcium in the perfusion buffer was followed by elevation of $\left[\mathrm{Ca}^{2+}\right]_{i}$, indicating the activation of CCE (Fig. 2D). If the latter finding is compared with CCE evoked by an agonist such as ATP or bradykinin, it is clear that CCE in the presence of 4-AP is potentiated (see Figs. $6 A, C$ ). This finding suggested that 4-AP interfered with CCE. To test whether CCE potentiation by 4-AP could modulate agonist-evoked calcium responses, we analyzed calcium transients after exposure to $\mathrm{InsP}_{3}$-linked agonists known to mobilize calcium from ICS. Astrocytes pre-exposed to 4-AP and then challenged with ATP or bradykinin displayed markedly changed calcium transient dynamics. In particular, the amplitude of the sustained phase of the calcium transient, an indicator of CCE, became larger and was significantly prolonged.

In the case of $10 \mu \mathrm{M}$ ATP, the pattern of $\left[\mathrm{Ca}^{2+}\right]_{\mathrm{i}}$ elevation in control cells was characterized by a spike followed by a lower but prolonged phase of $\left[\mathrm{Ca}^{2+}\right]_{\mathrm{i}}$ elevation (Fig. $5 A$ ). When astrocytes were pre-exposed to $10 \mathrm{~mm} 4-\mathrm{AP}$ and then challenged with $10 \mu \mathrm{M}$ ATP, the calcium transient induced by ATP lacked the initial spike but had a very high and prolonged plateau phase, which was promptly reversed by removing 4-AP from the perfusion medium (Fig. $5 B$; statistical validation is displayed in Fig. $5 E$, values were taken 2 sec before 4-AP removal).

Bradykinin responses were similarly affected by 4-AP. The typical spike-plateau response to bradykinin in control astrocytes (Fig. 5C) was, after treatment with $10 \mathrm{~mm}$ 4-AP, modified to a persistent high $\left[\mathrm{Ca}^{2+}\right]_{i}$ elevation, which was promptly reversed after washing out the 4-AP (Fig. 5D; statistical validation in Fig. $5 F$, values extracted $2 \mathrm{sec}$ before 4 -AP washout).

To further prove that 4-AP potentiates CCE, we designed a group of experiments in which $\mathrm{CCE}$ was measured. Control experiments were conducted to determine $\left[\mathrm{Ca}^{2+}\right]_{i}$ elevation in response to ICS depletion induced by three different paradigms. First, when ICS were depleted by ATP stimulation in the calciumfree $\mathrm{KRB}$, the reintroduction of calcium induced a very small $\left[\mathrm{Ca}^{2+}\right]_{\mathrm{i}}$ elevation (Fig. $6 A$ ). ICS were completely emptied by the ATP pulse, as shown by the lack of response to a second stimulation with ATP (Fig. 6A) or bradykinin (Fig. 6C). When the same experiments were performed in the presence of $10 \mathrm{~mm}$ 4-AP, CCE was greatly potentiated, when compared to ATP or 4-AP alone (Fig. 2D). In 4-AP-pretreated astrocytes, ATPinduced emptying of ICS triggered a large CCE after reintroduction of calcium in the extracellular medium. $\left[\mathrm{Ca}^{2+}\right]_{\mathrm{i}}$ rapidly rose to an extremely high plateau, which was maintained as long as 4-AP was present and promptly decreased to baseline, once the compound was washed out (Fig. 6B; see statistical validation in Fig. $6 E$, values extracted 2 sec before 4-AP washout). A similar CCE potentiation by 4-AP was seen after ICS depletion with bradykinin (Fig. 6D; statistical validation displayed in Fig. $6 F$, values extracted $2 \mathrm{sec}$ before 4-AP washout). The effect of 4-AP on CCE was concentration-dependent. A $5 \mathrm{~mm}$ concentration of 4-AP caused a smaller potentiation than $10 \mathrm{~mm} 4$-AP of CCE induced by ICS depletion with either ATP (control, $173 \pm 5 \mathrm{nM}$; $5 \mathrm{mmm} 4-\mathrm{AP}, 765 \pm 10 \mathrm{~nm} ; 10 \mathrm{~mm} 4-\mathrm{AP}, 1489 \pm 75 \mathrm{~nm})$ or bradykinin (control, $182+8 \mathrm{~nm} ; 5 \mathrm{~mm} 4-\mathrm{AP}, 488 \pm 16 \mathrm{~nm} ; 10 \mathrm{~mm}$ 4-AP, $1084 \pm 68 \mathrm{~nm}$ ).

In a second set of experiments, we analyzed CCE after depletion of ICS with thapsigargin, an irreversible blocker of the smooth endoplasmic reticulum calcium ATPase (SERCA), to exclude that the 4-AP potentiation of CCE observed after ATPand bradykinin-induced ICS emptying was not caused by interaction with secondary signal-transducing mechanisms activated by the two agonists. Exposure to a maximal concentration of 

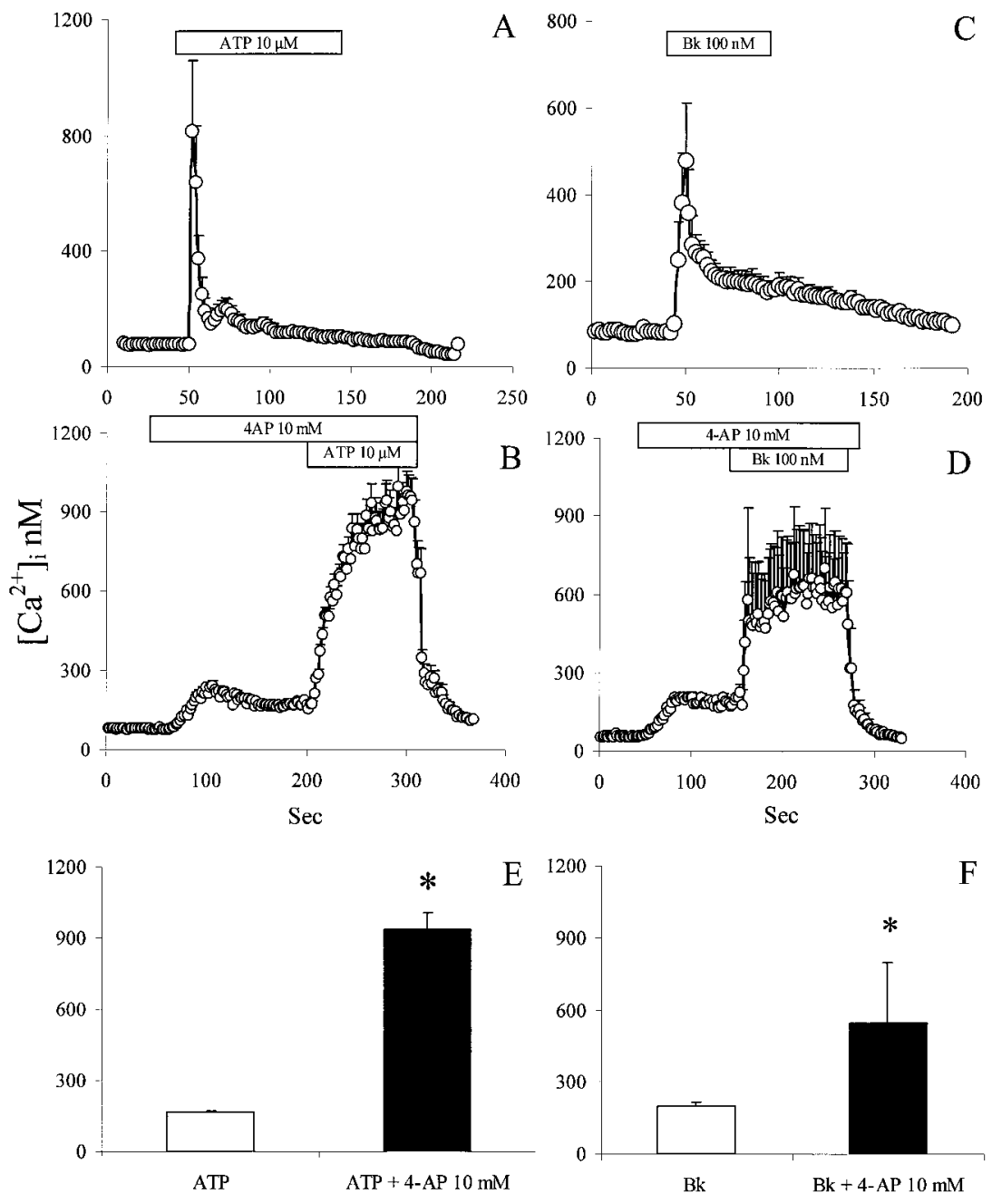

Figure 5. Effect of 4-AP on neurotransmitter-evoked calcium transients in astrocytes. Astrocytes were challenged with $10 \mu \mathrm{M} \operatorname{ATP}(A)$ or $100 \mathrm{~nm}$ bradykinin $(C)$. The calcium response to both agonists was characterized by a fast and sharp $\left[\mathrm{Ca}^{2+}\right]_{\mathrm{i}}$ elevation and a rapid return to a much lower but prolonged $\left[\mathrm{Ca}^{2+}\right]_{\mathrm{i}}$ value. Astrocytes preexposed to $10 \mathrm{~mm} 4$-AP and challenged with ATP $(B)$ or bradykinin $(D)$ showed a long-lasting large $\left[\mathrm{Ca}^{2+}\right]_{\mathrm{i}}$ elevation. $E$ and $F$ show statistical analysis of the data extrapolated from the experiments in $A$ and $C 2 \mathrm{sec}$ after agonist stimulation, and in $B$ and $D 2 \mathrm{sec}$ before 4-AP washout. ${ }^{*} p \leq 0.05$ versus value in control cells. Perfusion of the testing substances is indicated by the horizontal bars. thapsigargin $(10 \mu \mathrm{M})$ would also allow us assess the role of SERCA blockade in CCE potentiation by 4-AP (Fig. 7A). Thapsigargin, at $10 \mu \mathrm{M}$, applied with calcium-free KRB, completely discharged ICS. When calcium was reintroduced in the extracellular environment, a transient $\left[\mathrm{Ca}^{2+}\right]_{\mathrm{i}}$ elevation was triggered, which decreased to a lower steady-state $\left[\mathrm{Ca}^{2+}\right]_{\mathrm{i}}$ (Fig. $7 A$ ). When this experiment was conducted in the presence of 4-AP, CCE triggered by thapsigargin was powerfully potentiated (Fig. $7 B$; statistical validation presented in Fig. $7 C$, values were extrapolated at the peak of the response). We tested whether a similar phenomenon occurred in muscle cells and neurons. A strong potentiation of $\mathrm{CCE}$ induced by 4-AP was also observed in muscle cells (Fig. 8A, $B$; statistical validation is displayed in Fig. $8 C$, values were extracted $2 \mathrm{sec}$ before 4 -AP washout). On the contrary, potentiation of CCE by 4-AP was not observed in neurons (Fig. 3, compare $D, C$ ).

\section{4-AP inhibits voltage-dependent $\mathrm{K}^{+}$currents in astrocytes}

Astrocytes were voltage-clamped at a membrane voltage of -60 $\mathrm{mV}$. Fifty millisecond current pulses were delivered at $10 \mathrm{mV}$ intervals from $-80 \mathrm{mV}$ up to $+50 \mathrm{mV}$. Positive currents were recorded, and the resultant $I-V$ profile is shown in Fig. $9 A$. Currents measured $40 \mathrm{msec}$ after the start of each pulse were reversibly blocked by bath-applied 4-AP (10 mM) (Fig. $9 A$; sample traces displayed in Fig. $9 B$ ). The early, fast inactivating compo- nent, measured as the difference between the current 5 and 40 msec after the beginning of the pulse, did not recover from 4-AP blockade even after a 10 min washout (Fig. 9C). In addition, application of 4-AP did not significantly affect resting membrane potential of astrocytes held in current clamp (data not shown). Moreover, the contribution of other conductances at resting potential was negligible, because input resistance, measured with $100 \mathrm{pA}$ current injections, did not change after application of 4-AP $\left(I_{\text {in }}=32 \mathrm{M} \Omega+12\right.$ before and after 4-AP application $)$. The voltage-dependent $\mathrm{K}^{+}$channels blocker TEA $(20 \mathrm{~mm})$ reduced $\mathrm{K}^{+}$currents in a similar manner (Fig. 9D).

\section{Voltage-sensitive $\mathrm{K}^{+}$channel blockers have no effect on CCE}

To assess whether the effects of 4-AP on CCE resulted from blockade of voltage-sensitive $\mathrm{K}^{+}$channels, we analyzed the effect of specific blockers on CCE. We studied ATP-evoked $\left[\mathrm{Ca}^{2+}\right]_{\mathrm{i}}$ transients in astrocytes pretreated with $\alpha$-dendrotoxin (DTx), an inhibitor of the fast inactivating $\mathrm{K}^{+}$current (Ransom and Sontheimer, 1995; Rowan and Harvey, 1996; Frizzo and Barbeito, 1997). DTx did not potentiate CCE, although peak responses to ATP were affected (Fig. 10). The voltage-gated $\mathrm{K}^{+}$channel blocker TEA up to $120 \mathrm{~mm}$, did not affect CCE (data not shown). Simultaneous treatment of astrocytes with low concentrations of 4-AP $(500 \mu \mathrm{M})$ in combination with $50 \mathrm{~mm}$ TEA were not able to mimic the effect of $10 \mathrm{~mm} 4-\mathrm{AP}$ on CCE (data not shown). 
Figure 6. Effect of 4-AP on CCE triggered by agonistinduced ICS depletion in astrocytes. ICS were depleted with ATP $(A)$ or bradykinin in the absence of extracellular calcium. ICS emptying was controlled with a second ATP $(A)$ or bradykinin $(C)$ stimulation. When calcium was reintroduced, a weak $\left[\mathrm{Ca}^{2+}\right]_{\mathrm{i}}$ elevation was generated because of CCE activation. $B$, ICS were depleted with $10 \mu \mathrm{M}$ ATP in the presence of 4-AP. When calcium was reintroduced, $\left[\mathrm{Ca}^{2+}\right]_{\mathrm{i}}$ elevation was very high and lasted until 4-AP was removed from the cells. The same effect was recorded when stores were depleted with bradykinin in the presence of 4-AP $(D)$. $E$ and $F$ show the statistical validation of the data presented in $A-D$, respectively. Values were extrapolated from the experiments $2 \mathrm{sec}$ before removal of 4-AP. ${ }^{*} p$ value $\leq 0.05$ versus control cells. Perfusion of the testing substances is indicated by the horizontal bars.
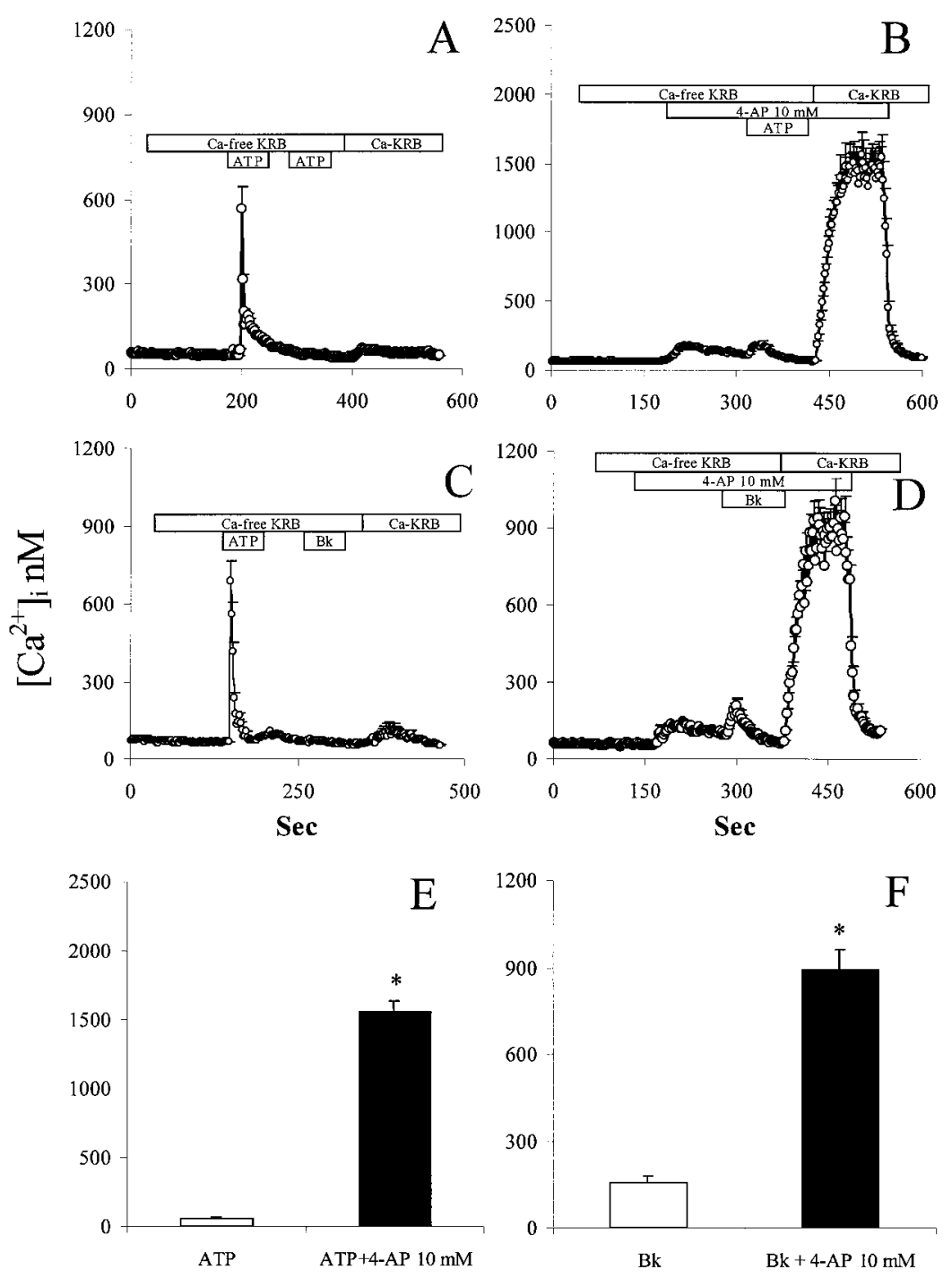

Because we found that $10 \mathrm{~mm}$ 4-AP caused a slight alkalization of KRB ( $\mathrm{pH} 7.8$ ), we conducted experiments to determinewhether changes in extracellular $\mathrm{pH}$ might have been involved in $\mathrm{CCE}$ potentiation. Increasing the $\mathrm{pH}$ of $\mathrm{KRB}$ up to 8.4 was not able to reproduce the effect of 4-AP on CCE (data not shown).

\section{DISCUSSION}

4-AP and its analogs have numerous clinical applications, including treatment of neuromuscular and neurodegenerative disorders and traumatic injuries of the CNS (Li and Z hang, 1994; Pinter et al., 1997; Fujihara and Miyoshi, 1998; Gruner and Yee, 1999; Segal et al., 1999; Andreani et al., 2000). All of the therapeutic activities of 4-AP are currently explained by blockade of voltageactivated $\mathrm{K}^{+}$channels (Vislobokoe et al., 1983; Davies et al., 1991; Choquet and Korn, 1992; Kirsch and Drewe, 1993; Castle et al., 1994). However, effects of 4-AP on calcium homeostasis have also been reported (Agoston et al., 1983; Pant et al., 1983; Tapia et al., 1985; Gibson and Manger, 1988; Campbell et al., 1993). Here, we show that 4-AP causes a complex change of
Figure 7. 4-AP potentiates thapsigargininduced $\mathrm{CCE}$ in astrocytes. $A$, Calcium stores were depleted with a maximal concentration of thapsigargin $(10 \mu \mathrm{M}) . B$, Thapsigargin exposure in cells pretreated with 4-AP resulted in a large increase of CCE. $C$, Statistical validation of the data presented in $A$ and $B$. Peak values were analyzed. ${ }^{*} p$ value $\leq 0.05$ versus control cells. Perfusion of the testing substances is indicated by the horizontal bars.
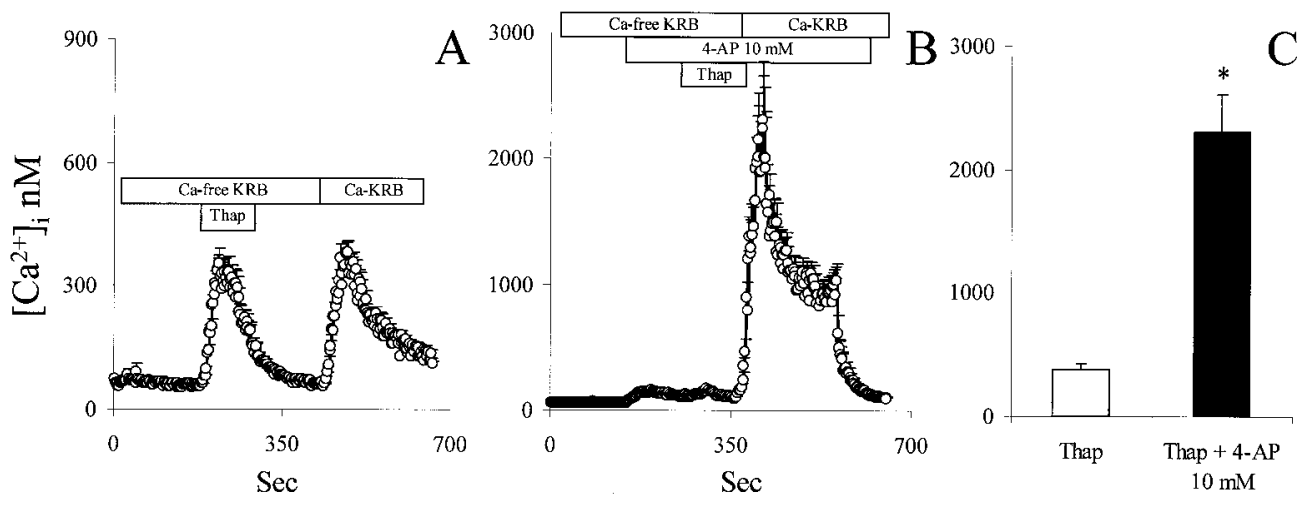

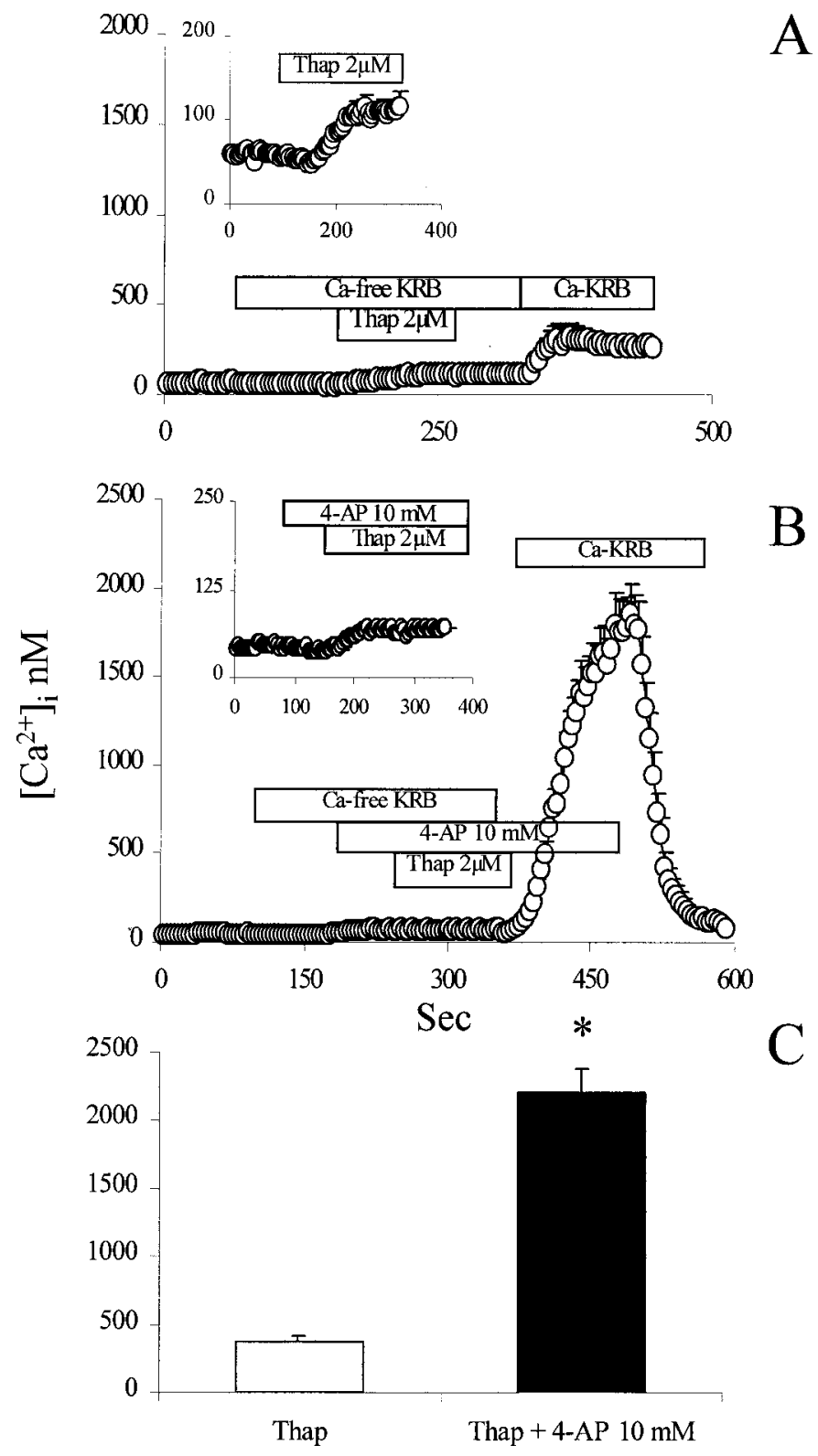

Figure 8. 4-AP potentiates CCE in L6 cells. A, Application of $10 \mu \mathrm{M}$ thapsigargin in calcium-free KRB caused an elevation of $\left[\mathrm{Ca}^{2+}\right]_{\mathrm{i}}$, (see inset to $A$ ). Reintroduction of calcium in the extracellular buffer was followed by CCE. The effect of thapsigargin alone it is highlighted in the inset. $B$, In the presence of $10 \mathrm{~mm} 4-\mathrm{AP}, \mathrm{CCE}$ was increased approximately ninefold. $C$, Statistical validation of the data extracted from control at peak and from 4-AP-exposed cells 2 sec before 4-AP washout. * $p$ value $\leq 0.05$ versus control cells. Perfusion of the testing substances is indicated by the horizontal bars.

calcium homeostasis, which includes mobilization of calcium from ICS, likely caused by $\mathrm{InsP}_{3}$ elevation, modulation of $\mathrm{InsP}_{3}$-linked calcium transients, and potentiation of CCE activated by ICS depletion. 4-AP modulation of calcium homeostasis may represent an additional molecular mechanism for the therapeutic actions of 4-AP and could be useful in the study of store-operated calcium channels.

The data we present show a weak and concentration-dependent increase of total InsP $\mathrm{P}_{\mathrm{t}}$ production in astrocytes and neurons after exposure to 4-AP. We hypothesize that this effect of 4-AP might be ascribed to an increase of PLC activity. Activation of PLC and subsequent production of $\mathrm{InsP}_{3}$ may be responsible for 4-APevoked calcium mobilization from ICS.

In addition, 4-AP appears to play a significant role in the regulation of calcium entering the cells after ICS depletion, a phenomenon known as CCE. CCE contributes to the magnitude and duration of agonist-evoked $\left[\mathrm{Ca}^{2+}\right]_{\mathrm{i}}$ transients, to calcium oscillation, and is the principal mechanism through which ICS are refilled (Putney, 1986). CCE is caused by the opening of the calcium release-activated calcium channel (CRAC) or storeoperated calcium channel (SOCC). This channel has been identified as homologous to the transient receptor potential channels in Drosophilae (Petersen et al., 1995). Here, we report that 4-AP potentiates CCE in astrocytes and muscle cells, but not in neurons. Other have already shown that 4-AP can inhibit SERCA (Ishida and Honda, 1993). The fact that in neurons 4-AP does not potentiate $\mathrm{CCE}$, although it increases resting $\left[\mathrm{Ca}^{2+}\right]_{\mathrm{i}}$, strongly suggests that the target of 4-AP is not present in neurons. Because SERCA is present in astrocytes as well as in muscle cells and in neurons, this strongly suggests that 4-AP potentiation of CCE does not involve SERCA. Furthermore, we show that blockade of SERCA with the irreversible inhibitor thapsigargin used at maximal concentrations (Thastrup et al., 1990) evoked CCE to a lesser degree than in the presence of 4-AP. When thapsigargin and 4-AP were added together, the resultant effect on CCE was synergistic. This would not be possible if the target of 4-AP action was only the SERCA. Therefore, we hypothesize that 4-AP may be acting on targets different than SERCA.

We also have demonstrated that 4-AP can potently prolong and increase $\left[\mathrm{Ca}^{2+}\right]_{\mathrm{i}}$ elevations caused by neurotransmitters such as ATP and bradykinin, which are linked to the intracellular messenger InsP $\mathrm{P}_{3}$. This latter evidence suggests that the physiology of the response to neurotransmitters can be modified when cells are exposed to 4-AP. This indicates that an interaction in vivo is likely to happen and will result in a longer duration of calcium transients. Because the effect of 4-AP alone on CCE is not so large as when it is triggered by a large calcium mobilization, we believe that other mechanisms must be activated to uncover the potentiation of CCE that we observed. When ICS are depleted either using an agonist able to cause a large production of $\operatorname{InsP}_{3}$, such as ATP or bradykinin, or an agent able to completely discharge ICS, such as thapsigargin, a robust signal is generated that triggers the opening of CRAC. Such a signal has not been definitively identified and characterized. However, in cortical type I astrocytes a soluble factor, probably belonging to the family of the eicosanoid derivatives (Rzigalinski et al., 1999), may be responsible for the opening of CRAC channel. Alternatively, a physical association between $\mathrm{SOC} / \mathrm{CRAC}$ and the $\mathrm{InsP}_{3}$ receptor, may be involved in the opening of the CRAC channel after the emptying of ICS (Boulay et al., 1999). Regardless of the signal used to trigger the opening of the CRAC channels, the presence of 4-AP causes a considerably larger influx of calcium from the extracellular space than in control cells. CR AC and voltage-sensitive $\mathrm{K}^{+}$channels have some similarity in the amino acid sequence (Harteneck et al., 2000), therefore, it is conceivable that 4-AP interacts with the open CRAC channels, in a similar manner to $\mathrm{K}^{+}$channels, and thereby increases CCE. The increased calcium influx coupled with the inability of the endoplasmic reticulum to sequestrate it, because 4-AP is blocking SERCA, would ultimately result in the great potentiation of CCE demonstrated in our experiments.

That 4-AP may interact with other targets cannot be excluded. In particular, ligand-gated calcium channels may participate in the calcium transient evoked by ATP (for review, see Burnashev, 
Figure 9. 4-AP inhibits voltage-gated $\mathrm{K}^{+}$ currents in astrocytes. $A$, Astrocytes were voltage-clamped at a membrane voltage of $-60 \mathrm{mV}$. Fifty-millisecond-long pulses were delivered at increasing voltages from $-80 \mathrm{mV}$ up to $+50 \mathrm{mV}$, at $10 \mathrm{mV}$ intervals. The $I-V$ profile was generated with a positive current that was recorded up to $\sim 2 \mathrm{nA}$ amplitude. The steady-state current was measured $40 \mathrm{msec}$ after the start of the pulse. $B$, Example traces recorded in astrocytes before, after exposure to 10 mM 4-AP and after washout. $C, 4-\mathrm{AP}$ application reversibly blocked the late component $(40 \mathrm{msec})$, whereas the early, fast inactivating component did not recover from blockage after $10 \mathrm{~min}$ washout (open bars are the normalized control current; black bars represent the currents after 4-AP application; hatched bars represent the amplitude of the current after $10 \mathrm{~min}$ washout). The fast component was calculated as the difference between the current at 5 and $40 \mathrm{msec}$ after the beginning of the pulse. $D$ displays the inhibitory effect of 20 mM TEA on potassium current in type I astrocytes. Control current was $\sim 1.38+$ $0.63 \mathrm{pA}$ and used as $100 \%$ in the open bar. $D$, The effect of $20 \mathrm{~mm}$ TEA is represented by the black bar. Cells were washed out, and the recovery of $\mathrm{K}^{+}$current is summarized in the hatched bar.
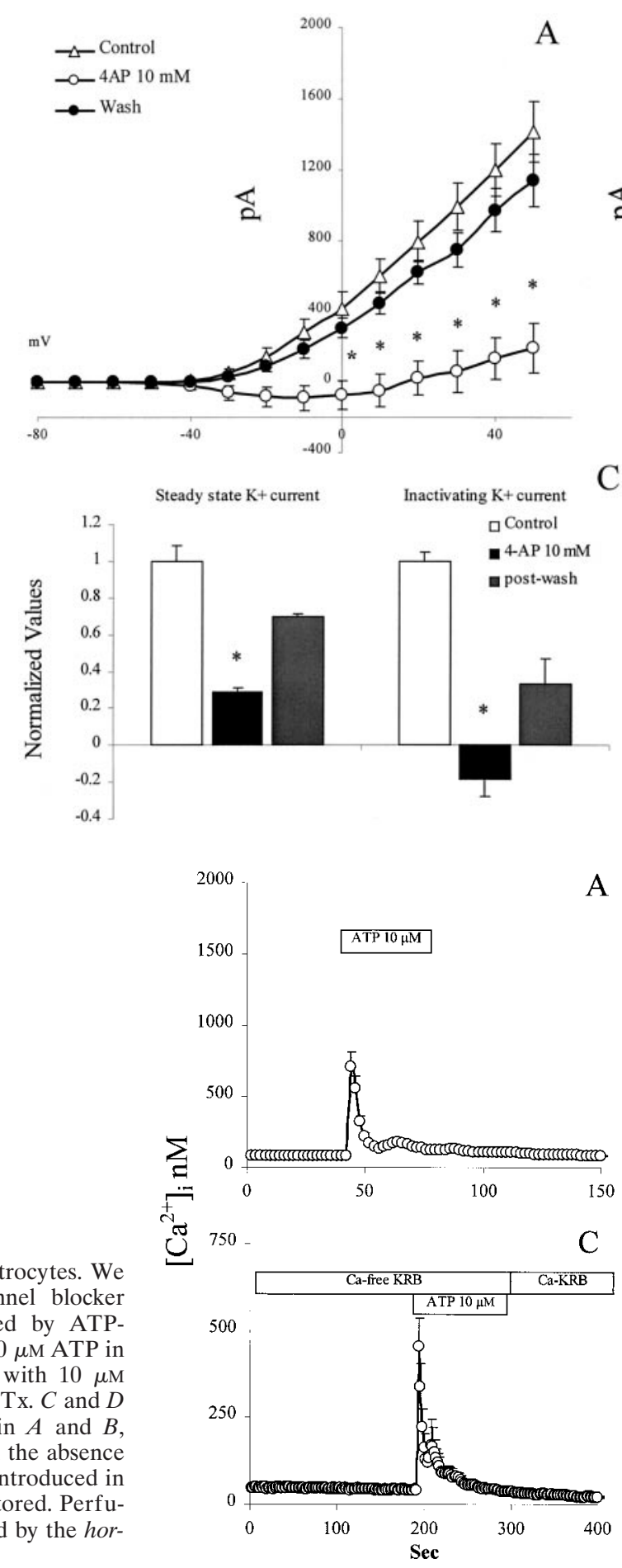

B
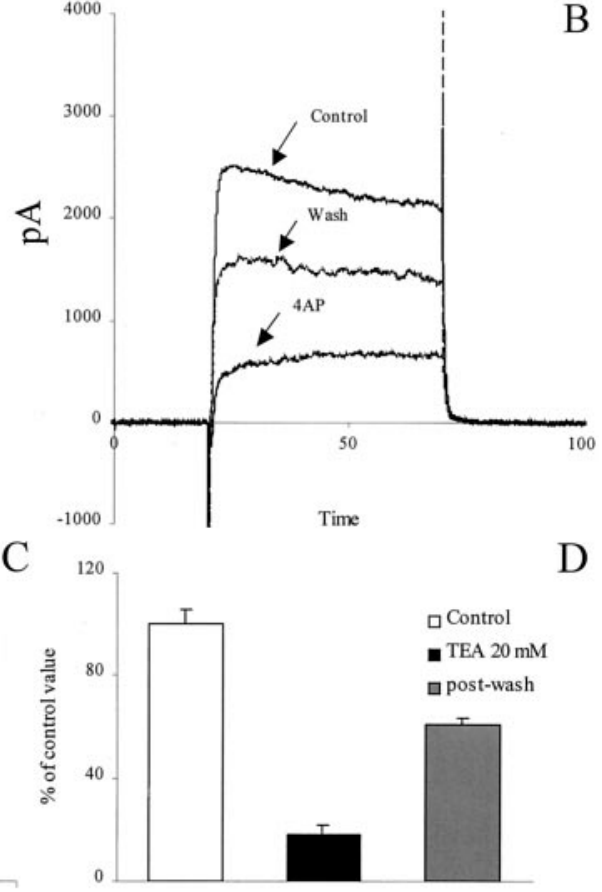

Figure 10. Effect of DTx on CCE in astrocytes. We tested whether voltage-gated $\mathrm{K}^{+}$channel blocker $\alpha$-dendrotoxin potentiatied CCE evoked by ATPinduced ICS depletion. $A$, Response to $10 \mu \mathrm{M}$ ATP in control cells. $B$, Cells were challenged with $10 \mu \mathrm{M}$ ATP after a 3 min exposure to 100 nM DTx. $C$ and $D$ were the same experiments as shown in $A$ and $B$, respectively, and they were performed in the absence of extracellular calcium. Calcium was reintroduced in the perfusion buffer, and CCE was monitored. Perfusion of the testing substances is indicated by the horizontal bar.
1998). However, the fact that 4-AP potentiates CCE when the ICS are depleted by thapsigargin suggests that these alternative mechanisms may participate but are not required.

Regardless of the mechanisms underlying CCE potentiation, the prolongation and potentiation of agonist-induced $\left[\mathrm{Ca}^{2+}\right]_{i}$ elevation may enhance excitation-contraction coupling of the muscle cells with a consequent improvement of neuromuscular function. Moreover, in the CNS such a potentiation of calcium responses may cause astrocytes to change their state of activation and to secrete trophic factors, which could play an important role in repairing mechanisms and in survival of surrounding neurons.
We have also shown that the effects of 4-AP are not attributable to blockade of voltage-sensitive $\mathrm{K}^{+}$channels. All experiments with different types of compounds affecting voltagesensitive $\mathrm{K}^{+}$channels were not able to reproduce the effect of 4-AP on CCE.

In conclusion, we report novel effects of 4-AP, namely mobilization of calcium from ICS, PLC activation, and the potentiation of agonists responses through a large potentiation of CCE. These actions may explain some of the therapeutic effects of 4-AP in disorders in which impairment of neurotransmission is involved. Moreover, changes in calcium homeostasis induced by 4-AP in 
astrocytes might cause the release of trophic factors that would likely support regrowth of neuronal extensions. Finally, we hypothesize that 4-AP potentiates CCE by interfering with SOC/ CRAC channels and may thus be a useful tool to study this channel for which specific agonists and antagonists are not yet developed.

\section{REFERENCES}

Agoston D, Hargittai P, Nagy A (1983) Effects of a 4-aminopyridine in calcium movements and changes of membrane potential in pinched-off nerve terminals from rat cerebral cortex. J Neurochem 41:745-751.

Andreani A, Leoni A, Locatelli A, Morigi R, Rambaldi M, Pietra C, Villetti G (2000) 4-Aminopyridine derivatives with antiamnesic activity. Eur J Med Chem 35:77-82.

Aronson JK (1992) Potassium channels in nervous tissue. Biochem Pharmacol 43:11-14.

Boulay G, Brown DM, Qin N, Jiang M, Dietrich A, Zhu MX, Chen Z, Birnbaumer M, Mikoshiba K, Birnbaumer L (1999) Modulation of $\mathrm{Ca}^{+}$entry by polypeptides of the inositol 1,4,5-trisphosphate receptor (IP3R) that bind transient receptor potential (TRP): evidence for roles of TRP and IP3R in store depletion-activated $\mathrm{Ca}^{2+}$ entry. Proc Natl Acad Sci USA 96:14955-14960.

Burnashev N (1998) Calcium permeability of ligand-gated channels. Cell Calcium 24:325-332.

Campbell DL, Qu Y, Rasmusson RL, Strauss HC (1993) The calciumindependent transient outward potassium current in isolated ferret right ventricular myocytes. II. Closed state reverse use-dependent block by 4-aminopyridine. J Gen Physiol 101:603-626.

Castle NA, Fadous SR, Logothetis DE, Wang GK (1994) 4-Aminopyridine binding and slow inactivation are mutually exclusive in rat Kv1.1 and Shaker potassium channels. Mol Pharmacol 46:1175-1181.

Choquet D, Korn H (1992) Mechanism of 4-aminopyridine action on voltage-gated potassium channels in lymphocytes. J Gen Physiol 99:217-240.

Davies NW, Pettit AI, Agarwal R, Standen NB (1991) The flickery block of ATP-dependent potassium channels of skeletal muscle by internal 4-aminopyridine. Pflügers Arch 419:25-31.

Frizzo ME, Barbeito L (1997) IA-type $\mathrm{K}^{+}$channel blockers promote survival of cortical neurons in culture: involvement of L-type $\mathrm{Ca}^{2+}$ channels. NeuroReport 8:1803-1806.

Fryer MW, Glover WE (1997) Effects of 4-methyl-2-aminopyridine on $[3 \mathrm{H}]$-noradrenaline overflow and contractility of isolated rabbit arteries. Gen Pharmacol 29:657-663.

Fu WM, Lin RH, Lin-Shiau SY (1987) Study on the neuromuscular action of 4-aminopyridine in the mouse diaphragm. Arch Int Pharmacodyn Ther 289:198-211.

Fujihara K, Miyoshi T (1998) The effects of 4-aminopyridine on motor evoked potentials in multiple sclerosis. J Neurol Sci 159:102-106.

Furukawa Y, Saegusa K, Chiba S (1985) The mode of action of 4-aminopyridine on the chronotropic and inotropic responses in the isolated, blood-perfused dog heart. Eur J Pharmacol 114:317-323.

Gibson GE, Manger T (1988) Changes in cytosolic free calcium with 1,2,3,4-tetrahydro-5-aminoacridine, 4-aminopyridine and 3,4-diaminopyridine. Biochem Pharmacol 37:4191-4196.

Glover WE (1981) Cholinergic effect of 4-aminopyridine and adrenergic effect of 4-methyl-2-aminopyridine in cardiac muscle. Eur J Pharmacol 71:21-31.

Gobet I, Lippai M, Tomkowiak M, Durocher Y, Leclerc C, Moreau M, Guerrier P (1995) 4-aminopyridine acts as a weak base and a $\mathrm{Ca}^{2+}$ mobilizing agent in triggering oocyte meiosis reinitiation and activation in the Japanese clam Ruditapes philippinarum. Int J Dev Biol 39:485-491.

Grimaldi M, Cavallaro S (1999) Functional and molecular diversity of PACAP/VIP receptors in cortical neurons and type I astrocytes. Eur J Neurosci 11:2767-2772.
Grimaldi M, Pozzoli G, Navarra P, Preziosi P, Schettini G (1994) Vasoactive intestinal peptide and forskolin stimulate interleukin 6 production by rat cortical astrocytes in culture via a cyclic AMP-dependent, prostaglandin-independent mechanism. J Neurochem 63:344-350.

Grimaldi M, Favit A, Alkon DL (1999) cAMP-induced cytoskeleton rearrangement increases calcium transients through the enhancement of capacitative calcium entry. J Biol Chem 274:33557-33564.

Gruner JA, Yee AK (1999) 4-Aminopyridine enhances motor evoked potentials following graded spinal cord compression injury in rats. Brain Res 816:446-456.

Grynkiewicz G, Poenie M, Tsien RY (1985) A new generation of $\mathrm{Ca}^{2+}$ indicators with greatly improved fluorescence properties. J Biol Chem 260:3440-3450.

Harteneck C, Plant TD, Schultz G (2000) From worm to man: three subfamilies of TRP channels. Trends Neurosci 23:159-166.

Ishida Y, Honda H (1993) Inhibitory action of 4-aminopyridine on $\mathrm{Ca}(2+)$-ATPase of the mammalian sarcoplasmic reticulum. J Biol Chem 268:4021-4024.

Kirsch GE, Drewe JA (1993) Gating-dependent mechanism of 4-aminopyridine block in two related potassium channels. J Gen Physiol 102:797-816.

Li L, Zhang YP (1994) Therapy of experimental autoimmune myasthenia gravis in rabbits with 4-aminopyridine and 3,4-diaminopyridine. Chung Kuo Yao Li Hsueh Pao 15:358-362.

Pant HC, Gallant PE, Cohen R, Neary JT, Gainer H (1983) Calciumdependent 4-aminopyridine stimulation of protein phosphorylation in squid optic lobe synaptosomes. Cell Mol Neurobiol 3:223-238.

Petersen CC, Berridge MJ, Borgese MF, Bennett DL (1995) Putative capacitative calcium entry channels: expression of Drosophila trp and evidence for the existence of vertebrate homologues. Biochem J 311: 41-44.

Pinter MJ, Waldeck RF, Cope TC, Cork LC (1997) Effects of 4-aminopyridine on muscle and motor unit force in canine motor neuron disease. J Neurosci 17:4500-4507.

Putney Jr JW (1986) A model for receptor-regulated calcium entry. Cell Calcium 7:1-12.

Ransom CB, Sontheimer H (1995) Biophysical and pharmacological characterization of inwardly rectifying $\mathrm{K}+$ currents in rat spinal cord astrocytes. J Neurophysiol 73:333-346.

Roe MV, Lemaster JJ, Herman B (1990) Assessment of fura-2 for measurements of cytosolic free calcium. Cell Calcium 11:63-73.

Rowan EG, Harvey AL (1996) Toxins affecting K+ channels. Braz J Med Biol Res 29:1765-1780.

Rzigalinski BA, Willoughby KA, Hoffman SW, Falck JR, Ellis EF (1999) Calcium influx factor, further evidence it is 5,6-epoxyeicosatrienoic acid. J Biol Chem 274:175-182.

Schwid SR, Petrie MD, McDermott MP, Tierney DS, Mason DH, Goodman AD (1997) Quantitative assessment of sustained-release 4-aminopyridine for symptomatic treatment of multiple sclerosis. Neurology 48:817-821.

Segal JL, Pathak MS, Hernandez JP, Himber PL, Brunnemann SR, Charter RS (1999) Safety and efficacy of 4-aminopyridine in humans with spinal cord injury: a long-term, controlled trial. Pharmacotherapy 19:713-723.

Smith KJ, Felts PA, John GR (2000) Effects of 4-aminopyridine on demyelinated axons, synapses and muscle tension. Brain 123:171-184.

Tapia R, Sitges M, Morales E (1985) Mechanism of the calciumdependent stimulation of transmitter release by 4-aminopyridine in synaptosomes. Brain Res 361:373-382.

Thastrup O, Cullen PJ, Drobak BK, Hanley MR, Dawson AP (1990) Thapsigargin, a tumor promoter, discharges intracellular $\mathrm{Ca}^{2+}$ stores by specific inhibition of the endoplasmic reticulum $\mathrm{Ca} 2(+)$-ATPase. Proc Natl Acad Sci USA 87:2466-2470.

Vislobokoe AI, Krylov BV, Akoev GN (1983) Predominant blocking of fast potassium current channels in mollusk neurons by 4-aminopyridine. Fiziol Zh SSSR Im I M Sechenova 69:1420-1426. 